Journal of Social Sciences 6 (1): 74-84, 2010

ISSN 1549-3652

(C) 2010 Science Publications

\title{
A Cost-Benefit Analysis of the Legalization of an Informal Health Sector
}

\author{
Roger Lee Mendoza \\ Cherry Hill, NJ 08003, USA
}

\begin{abstract}
Problem statement: The Philippines--a developing Southeast Asian country-exemplifies the co-existence of Western-oriented, medical science and indigenous, non-allopathic practices collectively known as Complementary and Alternative Medicine (CAM). The purpose of this study is to determine why and how the economics and politics of CAM's integration with biomedical science could impede the achievement of health care redistribution in developing countries like the Philippines. Approach: Representative case studies of CAM methods and content analysis of related legislation and policy initiatives were undertaken. Results: The study shed light on the problems, challenges and opportunities in addressing the misdistribution of primary and secondary health care in the Philippines. It found that subjective considerations underlie CAM's legitimacy. These become critical when scientific validity is at issue, information exchanged is asymmetric and political consensus is not readily available. How these considerations were valued from a cost-benefit perspective shaped actual policy outcomes. Conclusion: The study suggested that proper timing, phasing and collaborative strategies are critical to CAM's institutionalization in light of confining economic conditions and political conflicts over health policy. Both objective and subjective costs and benefits of CAM methods and products should be considered in integrating the formal (biomedical) and informal (CAM) health sectors, particularly in developing countries where health care is largely dependent on individual or household resource-based access and competitive prowess.
\end{abstract}

Key words: Allopathic medicine, biomedicine, asymmetric information, Complementary and Alternative Medicine (CAM), cost-benefit analysis, health care, informal economy, scientific validity, transaction costs

\section{INTRODUCTION}

In 1997, the Philippines passed the Traditional and Alternative Medicine Act (TAMA). Its enactment signaled a pro-active policy stance on the part of the Philippine government to promote health equity among disadvantaged Filipinos. Over a decade later, the consensus among many Filipinos is that the TAMA's health care redistribution goals have not yet been realized.

This study examines the Philippine experience in addressing health care availability, affordability and efficacy through the legalization of Complementary and Alternative Medicine (or CAM). It is guided by the following questions: What are the costs and benefits of institutionalizing CAM and integrating it with the formal health (biomedical) system in developing countries like the Philippines? How do these costs and benefits affect health care redistribution in these countries?

\section{POLICY FORMULATION}

Growth of the informal health system: Supply and demand: The informal sector of an economy consists of a wide range of paid or unpaid labor activities that are neither taxed nor monitored by government. It arises where earning opportunities are scarce and/or state regulations are too restrictive for certain economic activities to thrive (De Soto, 1989). The Philippine informal sector, like many developing countries, is estimated to contribute over $40 \%$ of GDP. It plays a significant role in creating employment, producing goods and services and augmenting income to help keep the economy resilient (Domingo, 2004).

The widespread practice of CAM as a source of primary and secondary health care underlines the growth and persistence of informal enterprise in the Philippines. The Department of Health reports that the ratio is about 1 CAM practitioner for every 300 Filipinos (World Health Organization, 2001a). In contrast, the doctor-population ratio is as low as 1 to 
over 26,000. Access to basic health care is complicated by the geographic misdistribution of physicians and health facilities and the continuing mass exodus of physicians for better pay and opportunities in other countries (Conde, 2004).

The uneasy coexistence of the biomedical and CAM systems in the Philippines exemplifies the Filipinos' conception of health as a function of both scientific knowledge and holistic wellness (Sy, 1997). That duality, in turn, stems from the country's diverse historical and cultural heritage:

A study of alternative medicine in the Philippines is, inevitably, a study of the origins of its people and the amalgam of cultures and influences: Centuries of Spanish colonial rule and the indelible consequences of its religion, hundreds of years of trade with China and assimilation of its healing arts, tribal and provincial diversities with its profusion of folklore and mythologies, all redounding into the Filipino's easy disposition for superstitions and the allure for the esoteric, mystical and fringe.

Certainly, western medicine prevails-in the metropolitan areas, with its heart centers and hospitals plush with the accoutrements of modern medicine, in the provincial capitals and cities equipped with the diagnostic machineries essential for the commerce of mainstream medicine. But for the majority of the rural poor - including the urban-suburban poor - there are the chronic crippling economic disabilities that make mainstream health care unaffordable, often accessed only as a debtinducing last resort (Philippine Alternative Medicine, 2008).

The World Health Organization defines CAM as comprising health practices, knowledge and beliefs that incorporate plant-based, animal-based and mineralbased medicines, spiritual therapies, manual techniques and exercises, whether applied singularly or in combination, to diagnose, treat and prevent illnesses or maintain personal well-being (World Health Organization, 2001b; 2002). CAM is invariably referred to as traditional medicine owing to the many indigenous sources of its practice. Western-based biomedical treatments, on the other hand, are based on the germ theory of disease. Filipino healthcare professionals generally remain suspicious and derisive of nonallopathic modalities. They tend to denigrate the practice of CAM to the herb doctor (albularyo), therapeutic chiropractic (hilot), faith healer (espiritista) and tribal medium (shaman).

The prevailing view that the informal sector poses obstacles to development and modernization has been gradually replaced by its treatment by governments as a hidden enterprise asset that should be harnessed (De Soto, 1989; Rakowski, 1994; International Labor Organization, 2002; Gerxhani, 2004) Opportunitydriven entrepreneurship has become widely recognized as a principal driver of economic growth that needs to be integrated with the formal economy, rather than simply eradicated (Minniti et al., 2006; Williams, 2006). In response to that challenge, a so-called "highroad" approach appears to be favored in many developing countries. It employs a combination of supply-side incentives for producers of informal sector goods and services (e.g., tax exemptions, training, research, information dissemination, auxiliary services) and demand-side initiatives to encourage consumers to use formal rather than informal labor (e.g., accreditation and professional standards to promote safety and confidence among consumers) (Cross, 1997, Williams, 2005; 2006).

The high-road approach was taken by the Philippines when it moved to legitimize the age-old but controversial practice and use of CAM in the early 1990s. Major supply-side factors to this initiative included: (1) a highly diverse flora compared to most countries, with about 1,500 of over 13,000 Philippine species already identified for their medicinal value; (2) large number of non-allopathic practitioners by reason of history, geography and culture; (3) growth in herbal medicinal research in the Asia-Pacific region and (4) international sources of funding and technical support (e.g., World Health Organization, United Nations Development Programme, World Bank). The demandside factors included: (1) dissatisfaction with conventional medicine (due to high cost, long waiting lines, invasive nature, adverse/side effects); (2) perceived need to gain control of personal health; (3) inaccessibility of physicians and medical facilities, particularly in rural and remote areas of the Philippines; (4) a global "new-age" allure for natural remedies (Pingoy, 2004) and (5) substantial economic potential in a \$250-million global market for medicinal plants vis-àvis diminishing foreign currency reserves and increased international debt of the Philippines in the 1990s.

In 1992, President Fidel Ramos and his Secretary of Health, Juan Flavier, launched a nationwide Traditional Medicine Program under the Department of Health for a period of 6 years (Department of Health Administrative Order No. 12, 1992). Technical support 
was offered by the World Health Organization. The program's most notable accomplishment was a 1995 health education campaign that identified 10 (out of 1,500) herbs for their safe (non-toxic) medicinal properties, subject to further scientific testing for any possible therapeutic effects. These herbs were akapulko, ampalaya, bawang, bayabas, lagundi, niyogniyogan, pansit-pansitan, sambong, tsaang-gubat and yerba buena (Department of Health Circular 168-A, 1995). The initial phase of political legitimation for the Ramos administration's program--restricted as it was to herbal research and promotion-expectedly encountered minimal opposition from physicians and drug companies. After all, the implementation of the program's substantive intent and content remained to be seen.

Economics and politics of legalizing CAM: To institutionalize CAM beyond the 6-year trial period and gain grassroots support, draft legislation was prepared in 1994 by the Ramos administration and authored in Congress by Flavier, who was by then a senator.

Flavier's bill proved highly contentious within and outside of the legislature. Metro Manila-based medical groups, led by the 28,000-strong Philippine Medical Association, expressed serious concern over the direction of the president's health policy. The proposed awareness training in non-conventional medicine for physicians was strongly resisted. Medical groups subsequently joined forces with multinational pharmaceutical firms in lobbying legislators against bill approval due to issues of quality control, safety and effectiveness. Some doctors also claimed that Ramos was fast-tracking the bill in support of his medical tourism program that seeks to attract foreigners to spend and invest in the Philippines, while seeking medical treatment.

The prospect of stiff competition with nonallopathic practitioners over patients could not be easily discounted. The Philippine Federation of Natural Health and Environment-Friendly Organizations held that many physicians and drug-makers were actually concerned about their diminishing economic viability in the wake of a fast-growing market for herbal products in the Philippines (Jorge, 2006). Flavier argued that his bill represented the long-standing struggle for freedom of medical choice by the Filipino majority who cannot afford the high cost of medicines and physicians fees, or were simply tired of conventional medicine (De Veyra, 2001).

Nonetheless, a political compromise was clearly needed to avoid congressional impasse and address the safety and quality control issues raised by the opposition. Flavier and his allies thus offered the creation of a regulatory and monitoring agency, which became the Philippine Institute of Traditional and Alternative Health Care (subsequently referred to as the "Institute"), a government corporation attached to the Department of Health. Physicians were assured of political representation in its governing board. The Institute was to promote and deliver CAM products, services, modalities and technologies that have been proven safe, effective, affordable and consistent with government standards on medical practice. It was also tasked to conduct research and skills-training in alternative healing methods and to formulate standards and guidelines governing their practices.

The successful passage of the TAMA (Republic Act No. 8423, 1997) can also be credited to the grassroots consensus-building and public relations strategies that the Department of Health adopted, with participation and funding from the World Health Organization and United Nations Development Programme. Consultations began through structured regional meetings with traditional healers, nongovernment organizations and local government officials. Meetings were arranged between healers and pharmaceutical companies. After two years of consultative assemblies, the Philippine Senate conducted formal hearings attended by health experts and stakeholders to garner credibility for Flavier's bill. The results of a United Nations Development Programme community study supported the efficacy of CAM approaches and helped identify partner nongovernmental organizations in the Philippines (Swiderska et al., 2001). The TAMA, however, did not contain any provision for feedback and evaluation mechanisms in spite of numerous provisions concerning CAM's educational, marketing and promotional aspects.

Costs and benefits of legalization: There is no gainsaying that the Philippine health care system has remained predominantly biomedical after 15 years of government promotional initiatives for the TAMA. There are still no privately-owned hospitals in the Philippines which officially offer CAM. Training of biomedical practitioners in CAM remains a priority of the government and, for the most part, continues to face stiff resistance from the medical profession. Natural medicines are marketed over the counter in dozens of health food stores or dispensed by CAM practitioners, especially in rural and remote parts of the Philippines, but are sold only by a small number of pharmacies. As a result, there is limited public information and awareness concerning the usefulness and limitations of specific CAM approaches and methods. 
From all indications, the institutionalization of CAM has not been largely or successfully accomplished beyond its legalization phase (i.e., Traditional Medicine Program of 1995 and the TAMA in 1997). The benefits of legalization have not also come without significant costs and risks and many of these appear to outweigh their intended benefits:

- No correlation exists between the use or popularity of CAM approaches and methods and scientific evidence about their safety and efficacy (Debas et al., 2006): CAM practitioners and patients avail of herbal therapies, natural products, or alternative modalities for a number of reasons: Indigenous traditions, folklore (e.g., beliefs about health), anecdotal evidence, convenience and sheer confidence. Seldom is their knowledge or understanding of CAM conditioned by scientific validity (Astin, 1998). On the other hand, the processes of scientific investigation and discovery can be tedious and cumbersome, as the specific cases presented in the next section indicate. Scientific evidence, no matter how inconclusive, can render many CAM therapies and modalities vulnerable to outright rejection by rival stakeholders who adhere to observable or measurable criteria (e.g., physicians' organizations, scientists and pharmaceutical firms).

- CAM's quest for legitimacy or credibility under the TAMA could degenerate into costly political battles, unless the government mediates and sets the parameters of debate: Rival stakeholders and their supporters may be encouraged to wage these battles if testing and validation are strictly confined to scientific criteria. A multidisciplinary approach to the issue of legitimacy may have to be encouraged by the government as public health regulator. The projected benefits of a multidisciplinary approach derive from consensual decision-making and attention given to the historical, cultural and psycho-social aspects of CAM in adjudicating legitimacy and utility claims.

- Despite the TAMA's stated objective of redistributing quality health care to the poor and disadvantaged, there is no indication that CAM is always cheaper or more accessible than conventional health care: No study has yet been done on the affordability of CAM for low-income Filipinos. However, studies of other developing countries show that many alternative remedies can be just as costly, if not more costly, than their biomedical or pharmaceutical counterparts (Winston and Patel, 1995; Muela et al., 2000). Without government regulation of the price mechanism and/or government stimulus programs (e.g., subsidies to herb farmers and manufacturers of natural products), the free market in the Philippines and other developing countries will inevitably operate based on consumer ability (or inability) to pay to the detriment of the less privileged.

- The vast economic potential of CAM cannot be realized without sufficient consumer demand for its products and services: The TAMA created the Institute and established a Development Fund to support job creation, research and training, production and marketing activities. The government's medical tourism program also exists to encourage investments in CAM-related industries, such as herb farming and eco-health resorts. However, asymmetric consumer information brought about by protracted stakeholder battles breeds confusion and deters participation in otherwise lucrative economic ventures. Asymmetric information can be costly for the consumers (e.g., costs of search and information relating to safety or efficacy), particularly when standards of practice, licensing and accreditation requirements and professional ethics are not in place or left for contestation by rival stakeholders.

- Integration of the formal and informal health care systems requires supply-side stimulation, which imposes significant costs to governments, particularly in developing countries: Tax incentives and deductions, research and practitioner training, health promotion and marketing programs, support services and lawenforcement (to address deceptive practices) can drain the meager resources of the government. A careful but deliberate determination of which therapies and modalities can be legitimately considered within the purview of the TAMA and which of them are simply recreational, leisure or sports-related regimens or activities is imperative.

- Information costs need to be equally addressed in integrating CAM with the formal health care system: An assertion that CAM promotes health care equity--and government intervention to support it is necessary-does not consider how consumer demand will be expressed, how costs and benefits will be valued, how conflicts will be resolved, or how science-based policies could be recast in terms of their presumed demerits. If consumer information about its risks and negative consequences are relatively high, that should support a decision against an alternative treatment; 
if low, that should encourage it. A value-laden choice is undeniably involved but can be qualified by symmetric information (adequate and balanced information available to all transacting parties). Consensus-building among stakeholders should be encouraged by the government where symmetric information is not readily available.

\section{POLICY IMPLEMENTATION}

Having examined the policy formulation process, the succeeding sections offer specific illustrations of the breadth and diversity of CAM approaches and methods. They allow us to examine the cost and benefits of TAMA's actual implementation in the Philippines, the emergence and resolution of competing stakeholder claims, the exchange of (frequently asymmetric) information between CAM producers/providers and consumers and the extent to which health policy could flow directly from scientific knowledge.

Therapeutic validation of lagundi: Lagundi (Vitex negundo) led the relatively uncontroversial path taken by four other medicinal herbs (tsaang gubat, sambong, akapulko and yerba buena) in acquiring therapeutic validation. The evidence-based practice to which the Institute and other government agencies subscribe--and which physicians, including a few who practice CAM, accept--distinguishes between herbal remedies with therapeutic or preventive value and those that are intended as dietary supplements. At the heart of this often long and tedious investigation lies the search for active ingredients (i.e., what makes the herb therapeutic and why) (Tan, 1996; Jorge, 2006).

The lagundi case illustrates the legitimizing function of scientific knowledge. An indigenous chaste tree, lagundi had long been prescribed by many physicians for cough/sore throat, fever and asthma relief. Its decocted leaves and roots have been used for ages by herb doctors to treat dyspepsia, colic, rheumatism, worms, boils and leprosy. Some active ingredients had been previously identified for lagundi and the four other herbs based on clinical studies performed in the pre-TAMA period. Thus, while the completion of more conclusive studies took time, the biomedical community had objective and symmetric information about lagundi's anti-histamine and anti-inflammatory properties. Official endorsement by the Department of Health was virtually a fait accompli. In 1996, lagundi was approved for commercial production and distribution in the form of medicinal tablets for cough, cold, fever and asthma relief, along with tsaang gubat as an anti-diarrheal, yerba buena as an analgesic, akapulko to treat fungus and skin conditions and sambong for kidney stones and hypertension (Icamina, 2008).

However, the costs of protracted validation cannot be understated. It has hampered consumer interest in and demand for natural medicines. In turn, it has failed to stimulate job creation in otherwise economically viable Philippine industries (such as herb agriculture, herbal manufacturing). Evidence-based practice can also be exclusionary from the standpoint of CAM practitioners (e.g., capsules and syrups from proven therapeutic herbs can only be physician-prescribed).

The isolationist and deductive nature of scientific testing has become a focal point in the ongoing debate about the efficacy of herbal medicines. Herbalists claim that "there's no way of identifying the active ingredient" because what makes alternative medicines work is "the belief that they would work" (Jorge, 2006). Such anti-thesis of science partly explains CAM's public allure (Tan, 1987) and illustrates the difficulty of achieving political consensus during actual policy implementation.

The ampalaya controversy: The case of ampalaya or bitter melon (Momordica charantia Linn) offers a sharp contrast to lagundi in view of the former's unexpected policy consequences and the clash of powerful, vested interests that derailed its quest to gain therapeutic status.

The Department of Health had vigorously promoted ampalaya as a reasonably priced food supplement, since most diabetic Filipinos are unable to afford diamicron and other pharmaceutical brands. By the mid-1990s, various ampalaya supplements had appeared in Philippine markets, many of dubious efficacy. Ampalaya processed products were also aggressively advertised by domestic and foreign manufacturers. Their popularity among Filipinos immediately cut into the sales of the pharmaceutical industry's (often imported) anti-diabetes drugs (Bautista-Alcaraz, 2007).

Multinational drug companies thus led the lobby for ampalaya 's immediate recall (Mercado, 2003). The Secretary of Health succumbed to political pressure and ordered ampalaya delisted from the Big 10 in 2003, even without the knowledge of and coordination with the appropriate Philippine regulatory agencies. To appease herbalists, ampalaya was (ridiculously) reclassified or downgraded as a "folklorically validated medicinal herb ... due to lack of evidence on the clinical efficacy of ampalaya against diabetes mellitus" (Department of Health Circular No. 196-A, 2003). Herbalists and producers of ampalaya-based supplements countered that delisting only gained for 
multinational firms exclusive rights to manufacture and market pharmaceuticals (Mariano, 2007a).

The delisting order quickly unfurled its devastating impact on the Philippine economy. The market for ampalaya supplements shrank by 80 percent in less than three years since 2003. As many as 10 of 15 Filipino companies that used to manufacture ampalaya supplements and by-products were forced to close down causing unemployment, disinvestments, hard currency flight and business dislocations in the Philippines (Mariano, 2007a). Government stimulus programs for ampalaya farming were put on hold.

Interest groups led by the Philippine Herbal Health Care Association and the Chamber of Herbal Industries of the Philippines soon petitioned for the restoration of ampalaya to its former status. The herbalists' campaign appeared to have further benefited from newly completed studies that upheld ampalaya's medicinal qualities, including the discovery of Charantia Ampalaya tea for the special dietary needs of diabetics. After nearly 4 years of placing ampalaya in a state of suspended animation, the Department of Health reversed itself. It restored ampalaya as a scientifically validated, medicinal plant (Department of Health Circular 2007-0058, 2007).

However, ampalaya's reinstatement fell short of a major victory for CAM practitioners and advocates. In reality, only ampalaya leaves (in fact, only the leaves of a single variety called Makiling) were clinically-proven for diabetes treatment due to an active ingredient known as polypeptide-P (Mercado, 2003). To date, no conclusive clinical study has ever been done on the therapeutic efficacy of ampalaya's fruit, vine, roots and seeds.

Because the therapeutic and preventive values of ampalaya were restrictively defined, the reinstatement order was not too costly to pharmaceutical firms. For one, the 2003 delisting order had already taken its toll on many existing market rivals, while emergent rivals encouraged by the 2007 reinstatement order were expected to be far less in number given a narrower consumer market. Drug-makers were also satisfied that reinstatement did not pass upon the validity of ampalaya or its natural products as emetics and laxatives, or for treating other illnesses (Bureau of Plant Industry, 2009), which are more lucrative from a market standpoint. Finally, because ampalaya tablets could only be taken upon a doctor's prescription, the reinstatement order allayed the medical profession's concern about marketing ampalaya as a cure-all dietary supplement.

The ampalaya case demonstrates how the costs and benefits of policy outcomes are valued and recalculated by stakeholders, particularly since the results of scientific investigation are often incremental and inconclusive. The delimited efficacy of herbal therapies and natural products have as much potential for conflict resolution as for undermining CAM's anti-reductionist and holistic framework. It is this careful balancing of competing (and perhaps equally compelling) stakes that creatively tests the government's regulatory function.

Iridology: The practice of medical unorthodoxy: Iridology represents for the purpose of this study those diagnostic and prescriptive modalities that are either beyond scientific validation or without scientific basis. To this group belongs chelation, homeopathy, electromagnetic medicine, detoxification, light and color therapy and hyperbaric medicine. The growing popularity of these less costly (i.e., less expensive and relatively painless) modalities among Filipinos has created far greater sources of conflict and tension in TAMA's implementation.

Iridology involves the evaluation of patterns, colors and blood vessels of the iris (colored part of the eyes) to detect which body organs are healthy and which are not. This is premised on the assumption that the different zones of the iris correspond to parts of the human anatomy. One report identified iridology as the most popular alternative health care modality in the Philippines due to direct marketing and aggressive advertising by its proponents (Philippine Academy of Opthalmology, 2006).

The Philippine Medical Association and the Philippine Academy of Opthalmology have been consistently at odds with iridologists and similar practitioners since the TAMA's passage:

Eye examinations, along with other more definitive tests, can indicate to a physician if a patient has liver problems. But can iridology clinicians truly diagnose all the diseases of a person through the minute vessels of his eyes alone?

Chelation is a vital medical procedure to rid victims of heavy metal poisoning of their toxins. But is it of any value to those with heart disease when cholesterol and not calcium are seen as the chief cause of the hardening of arteries?

It's Ayurvedic medicines with heavy metals. It's Chinese traditional medicines made from endangered species. ... It's pranic healing that balances "chi" energies. It's 
"quantum healing" that by definition fails to define itself. What's a befuddled Filipino to do? The confusion is enough to make anyone sick.

Clearly, it is a matter of claims and evidences. The sweeping assertions of cure-alls and the all-encompassing diagnostic techniques of pseudo science are causes for alarm (Jorge, 2006).

In 2006, the Philippine Academy of Opthalmology published a position paper that derived empirical support from all published, double-blind studies of iridology. It asked the government to delegitimize iridology for being totally flawed ("no better than chance"), harmful ("irreversible blindness," "serious complications have been reported"), deceptive ("peddling" of "unregulated supplements") and outright illegal (prescriptive) (Philippine Academy of Opthalmology, 2006). Iridologists initially managed to present a well-funded, united front, as they claimed that their practice was synergistic ("quantum healing") and, therefore, misunderstood by the medical community. Later, the iridology-supportive Philippine Federation of Natural Health and Environment-Friendly Organizations asserted that iridology was merely a diagnostic tool. The Philippine Medical Association debunked these claims by citing iridologists in Baguio, Quezon and Aklan who prescribed medicine instead of referring them to medical specialists (Jorge, 2006). As the direct confrontation with medical groups became imminent, iridologists led by the Guardo Brothers' Osaka (iridology clinics) intensified their media advertisements and employed deceptive testimonials by local actors. That appeared to be the final straw for the Philippine Medical Association, which issued a Joint Manifesto with various advertising and broadcasters' associations in 2006 urging the government to decide immediately.

The long-drawn, bipolar conflict over iridology underscores the crucial role of government as regulator of public health. As the two sides accused each other of ill will, the Department of Health and the Institute preferred to keep a hands-off approach given the absence of iridology standards of practice and code of ethics. In effect, government officials relegated to stakeholders the resolution of the contentious issue of legitimacy, besides inviting them to meet occasionally to address regulatory and research matters (Eleazar, 2003). The TAMA also drew criticism for failing to confer any policing powers on the Institute that would have significantly increased the costs of deceptive health marketing.
In late 2008, amid growing public clamor for a final decision, the Department of Health moved to break the political stalemate in favor of conventional medicine. The health secretary stripped iridology of its erstwhile alternative modality status under the TAMA due to lack of any "evidence of having value either for diagnosis or treatment of diseases" (Department of Health, 2008). The Institute also issued a public warning about its lethal consequences when it steers away patients from necessary medical treatment (Evangelista, 2008). These virtually led to the demise of iridology and paved the way for the biomedical professions to train their sights on other questionable modalities, like chelation and homeopathy. However, many Filipinos wondered why it took the government more than a decade and many more documented cases of harm, to rule on the legitimacy of a "sick" modality.

The iridology case shows how popular demand and support for a flawed modality can arise out of a combination of personal calculations of gain (cheaper, accessible and non-invasive procedure) and the organized power and deception of certain CAM providers. Unfettered market competition supports that combination when regulatory oversight is in short supply and the information exchanged between producers (or practitioners) and consumers of CAM is asymmetric in favor of the former. Another crucial lesson from the iridology case is that passivity on the part of government helps intensify political conflict. It subverts efforts to achieve fair and speedy resolution of competing claims or, at the very least, to reduce adversarial relations among rival stakeholders (e.g., by developing licensing and registration requirements).

Reflexology: Delimiting legislative intent: Reflexology was selected in this study to illustrate those alternative modalities that incorporate massage, physical exercise and contemplation/meditation and are essentially non-diagnostic and non-prescriptive in nature. These include massage therapy, chiropractic medicine, acupressure, Ayurveda, aromatherapy and no-touch pranic healing. Many have been officially endorsed by the Institute even prior to their validation (Galindez, 2006).

With the exception of the sub-urban and rural hilot and espiritista, the vast majority of practitioners in this field operate within the formal sector of the economy. The upper-middle and upper classes--who generally regard wellness and fitness as integral "lifestyle components"--are their target clientele. Many proprietors of wellness and fitness facilities are also politically well connected, which help explain the relative ease with which they have been accorded 
government recognition and benefited from its health promotion programs, such as the wellness clinic model (Eleazar, 2003; 2004). The Institute has strongly supported medical tourism by encouraging foreign investments in medi-spas, wellness clinics, eco-health resorts and health farms (Galindez, 2006).

The "commodification" of health care under the TAMA raised by the biomedical professions stems in part from the law's a priori designation of several wellness and fitness regimens as covered modalities. In doing so, these TAMA provisions unintentionally offer economic incentives to operate massage clinic, spas, gyms and similar facilities on the spurious health marketing claim that they constitute legally recognized forms of CAM. Where legislative coverage can be overstretched for purely personal gain (i.e., free riding) despite the prescription for government oversight, even groups of dubious distinction (e.g., cosmetology clinic owners) could legally claim equal treatment and benefits from government by making analogies of their products and services to the TAMA-covered modalities.

The TAMA identified reflexology as a modality, but it has not evaded controversy since then. Reflexology is based on the belief that parts of the human feet (and sometimes the hands and ears) correspond to bodily parts. Reflexologists rely on acupressure on specific zones to stimulate corresponding organs to heal themselves. Even disregarding their unverified claims, no consensus exists among reflexologists as to how these organs are supposed to work. Their claims of unblocking the flow of "vital energies" of "crystalline deposits" do not correspond to the current understanding of human anatomy. Acupressure itself has been repeatedly questioned by the Philippine Medical Association as a covered modality under TAMA. Most physicians see reflexology and acupressure only as stress-relievers rather than actual healing arts.

The lack of consensus over reflexology's credibility has delayed accreditation and licensing standards for other alternative modalities and correspondingly slowed down the TAMA's implementation. It has also pushed the Institute--which has increasingly received public criticisms of regulatory ineffectiveness--toward the uncomfortable political middle ground (Mariano, 2007b). The conflict over reflexology peaked in 2006, when the Philippine Medical Association urged the government in a publicized manifesto to refrain from endorsing reflexology, massage, acupressure, aromatherapy, myofacial therapy and other therapies, prior to their scientific validation due to adverse health effects and unregulated practice. Reflexologists appear undeterred by these criticisms. To date, they continue to press for government-approved standards of practice, a national certification program and a British-style practitioners' registry or database (Ciriacruz, 2003).

One key insight from the reflexology case is that problems arise when the efficacy of an alternative modality cannot be easily proven and its expected results do not extend beyond the exclusive, leisure/recreational benefits to the individual. In contrast, governments endorse and support CAM (as a merit good) because its health benefits to society in general exceed private consumer benefits (Mulligan and Philipson, 1999). Preserving the status quo (no exclusion but no official accreditation) may be the most politically convenient and acceptable Philippine government response to some questionable healing methods, like reflexology or acupressure. However, only time can tell if it is creative enough to allow new, consensual validation models and processes to evolve and settle questions and concerns about these controversial modalities.

Lessons and insights from TAMA's implementation: The case illustrations in this study offer valuable lessons and insights for other countries in implementing CAM-related health care policies:

- Legalization and professionalization will inevitably involve testing and validation: How CAM's non-measurable, "synergistic effects" can be tested and/or validated require consensusbuilding, along with a mix of government oversight, consultation with health and policy experts, accreditation, licensing, professional standards of practice and ethics and continuing education.

- CAM's felt effectiveness-whether imagined or real--may be valued more than its scientific legitimacy (or despite its scientific illegitimacy): Normative and axiological considerations equally underlie consumer perceptions of CAM's legitimacy and credibility. This calls attention to the need for greater public information about the costs and risks of using CAM approaches, methods and products. The importance of government monitoring and regulation, public education, research and information dissemination cannot be understated.

- Conflict resolution demands more than just an umpire or arbiter role for the government: Government passivity to avoid controversy sends the wrong signals to CAM consumers and producers/providers alike. It makes it difficult to 
contain subjective claims, deception and asymmetric information that can easily breed public confusion or disaffection in making decisions or choices over primary and secondary sources of health care. Passivity also neglects the feedback effects of key policy inputs.

- Agency effectiveness is critical to the successful integration of a dual health care system: Effectiveness goes beyond legislative delegation of power and responsibilities. Prompt action and coordination in establishing standards of practice, codes of ethics, accreditation and licensing procedures, practitioner registries and monitoring mechanisms, as well as enforcing sanctions, are critical to policy implementation. The effectiveness of implementing agencies of government should be regularly evaluated.

- Legislative scope and intent need not be allinclusive: Any CAM legislation or policy that is too inclusive is bound to encourage free-riders and unduly extend privileges beyond its original intent and before alternative methods can gain validity or legitimacy. Legislative policy should not hamper validation or legitimation processes.

- Conflict-resolution processes rearrange production and consumption incentives and disincentives: Validated treatment methods and products induce practitioner and consumer interest and reliance. Protracted controversies and subjective government rulings impose drastic economic and development burdens on the part of the state. Policy implementation should be treated as a dynamic and ongoing process of developing, promoting, monitoring and evaluating CAM's effectiveness.

- Transaction costs will be burdensome to stakeholders and regulators unless they are specifically and carefully addressed: Several zero-sum (win-lose) battles that figured prominently under the TAMA could have been less adversarial, or totally avoided, if public preferences were gauged and initially made known to stakeholders and regulators. Conversely, public confusion and disaffection arising from competing claims could be significantly reduced by effective information dissemination undertaken by the government. The unimpeded flow of vital information reduces heavy transaction costs (particularly the costs of bargaining, marketing, advertising and enforcement) that affect policy outcomes (Dahlman, 1979). How to institutionalize public participation in the policy process presents a challenge and opportunity to any government.
- Health care availability, affordability and efficacy goals are better served when policy debates are not confined to a single, key source of cleavage: Too often, there is an implicit assumption that policy choices involving CAM are binary (premised on the approval or rejection of a given treatment) and bipolar (advocated by two, mutually repellent sides). That view restricts policy options and strategies, consensus-building and informed consumer judgment. A careful balancing of the empirical and value orientations of health policy choices is therefore imperative.

\section{CONCLUSION}

The Philippine experience with the TAMA demonstrates the intended and unintended consequences of seeking to integrate the allopathic and non-allopathic health sectors in developing countries. The normative, axiological and bioethical dimensions of CAM approaches, methods and products may be less objective than what the processes of scientific validation and professional accreditation may suggest. Yet, they are just as critical to CAM's long-term success in making quality health care available and affordable, especially to the poor and disadvantaged population. The challenge to governments in many developing countries is to seek a net outcome from CAM's aggregate costs and benefits that is both socially redistributive from a consumer standpoint and economically viable to its providers.

This study finds that a pro-active policy stance by governments should be adopted with proper timing, phasing and collaborative strategy to efficiently address confining economic conditions and ensuing political conflicts. One main effect of the TAMA has been to draw attention to the need to correct the prevailing misdistribution of health care, whether or not integration of a dual health system is the best way of doing so. The Philippine experience also suggests the practical advantage of incremental changes and transitions involving an informal economy like CAM. These are particularly critical in countries where free market forces operate naturally to limit health care access based on the competitive economic prowess of individuals and households.

\section{REFERENCES}

Astin, J.A., 1998. Why patients use alternative medicine: Results of a national study. J. Am. Med. Assoc., 279: 1549-1553. http://jama.amaassn.org/cgi/content/full/279/19/1548 
Bautista-Alcaraz, O., 2007. DOH reinstates Ampalaya. Manila Bulletin.

http://www.bpi.da.gov.ph/Publications/mp/html/a/a mpalaya.htm

Bureau of Plant Industry, 2009. Department of Agriculture.

http://www.bpi.da.gov.ph/Publications/mp/html/a/a mpalaya.htm

Ciriacruz, M., 2003. Alternative appeal: As alternative modes of healing gain popularity, PITACH gives primary care the priority. MedObserver. http://www.upd.edu.ph/ serdef/Natural\%20health $\% 20$ Industry\%20in\%20General/Alternative\%20Ap peal.doc

Conde, C.H., 2004. Special report: A sick health care system. $\quad$ Bulatlat, $4:$ 2. http://www.bulatlat.com/news/4-37/4-37-sick.html

Cross, J.C., 1997. Entrepreneurship and exploitation: Measuring independence and dependence in the informal economy. Int. J. Soc. Soc. Policy, 17: 3763. DOI: 10.1108/eb013300

Dahlman, C. J., 1979. The problem of externality. J. Law Econ., 22: 141-162. DOI: 10.1086/466936

De Soto, H. 1989. The Other Path: The Economic Answer to Terrorism. Harper Collins, London, ISBN: 10: 0465016103.

De Veyra, E.B., 2001. Flavier bats for alternative medicine. Manila Bulletin. http://www.highbeam.com/doc/1G1132035916.html

Debas, H.T., R. Laxminarayan and S.E. Straus, 2006. Complementary and Alternative Medicine. In: Disease Control Priorities in Developing Countries, Debas, H.T. et al. (Eds.)., 2nd Edn., Chapter 69, The World Bank and Oxford University Press, Washington DC., NY., ISBN: 10: 0-82130821361791, pp: 1281-1291.

Department of Health, 2008. DOH Cautions Public on Iridology, Press Release of Secretary Francisco T. Duque, Manila. http://www.doh.gov.ph/node/2089/print

Domingo, E.V., 2004. Measuring the Non-Observed Economy (NOE): The Philippine Experience. Proceeding of the OECD/UNESCAP/ADP Workshop on Assessing and Improving Statistical Quality: Measuring the Non-observed Economy, May 11-14, Bangkok, Thailand, pp: 1-19. http://www.unescap.org/stat/meet/wnoe/waisq_phil ippines.pdf

Eleazar, G.B., 2003. Philippines Country Report. WHO Regional Meeting on Network for Policy and Programme Development in Traditional Medicine, Dec. 11-13, Shanghai, China, pp: 1-1. http://www2.doh.gov.ph/pitahc/China2003.html
Eleazar, G.B., 2004. Country report. ASEAN Ad Hoc Working Group Meeting on Traditional and Complementary Medicine, Apr. 17-17, Penang, Malaysia. http://www2.doh.gov.ph/pitahc/Malaysia2004.html

Evangelista, K., 2008. DOH warns against Iridology. Philippine Daily Inquirer. http://showbizandstyle.inquirer.net/breakingnews/b reakingnews/view/20080804-152616/DOH-warnsagainst-Iridology

Galindez, C.R., 2006. Complementary and Alternative Medicine: A Prescription for Medical Tourism. PITAHC, Manila, pp: 29-36.

Gerxhani, K., 2004. The informal sector in developed and less developed countries: A literature survey. Public Choice, 120: 267-274. DOI: 10.1023/B:PUCH.0000044287.88147.5e

Icamina, P.M., 2008. Herbals passed scientific tests, proven effective. Sunday Times.

International Labor Organization, 2002. Decent Work and the Informal Economy. International Labor Organization, Geneva, ISBN: 92-2-112429-0.

Jorge, R., 2006. Money and medicine: The fight over conventional drugs and alternative healing. Sunday Times.

Mariano, D., 2007a. No angels in business suits. The Manila Times.

Mariano, D., 2007b. TAMA of 1997 already mandates cheap medicine. The Manila Times.

Mercado, J.L., 2003. 'Bitter melon war' roils health front. Sun Star Cebu.

Minniti, M., W. Bygrave and E. Autio, 2006. Global Entrepreneurship Monitor: 2005 Executive Report. London Business School, London.

Muela, S.H., A.K. Mushi and J.M. Ribera, 2000. The paradox of the cost and affordability of traditional and government health services in Tanzania. Health Policy Plann., 15: 296-302. http://heapol.oxfordjournals.org/cgi/reprint/15/3/296

Mulligan, C. and T.J. Philipson, 1999. Policy design and incidence in a merit good economy. University of Chicago. http://www.spc.uchicago.edu/prc/pdfs/Mulligan.pdf

Philippine Academy of Opthalmology, 2006. Iridology: Position Statement. Manila, http://www.pao.org.ph/PDF/controversies/IRIDOL OGY080706PM.pdf

Philippine Alternative Medicine, 2008. Herbal therapies. http://www.stuartxchange.com/AltMedIntro.html

Pingoy, D., 2004. CAM use at the cancer institute. Philipp. J. Intern. Med., 42: 159-171. 
Rakowski, C.A., 1994. The informal sector debate, Part II: 1984-1993. In: Contrapunto: The Informal Sector Debate in Latin America, Rakowski, C.A. (Ed.). State University of New York Press, New York, ISBN: 0-7914-1905-3.

Swiderska, K., E. Daño and O. Dubois, 2001. Developing the Philippines' executive order No. 247 on Access to Genetic Resources. International Institute for Environment and Development, London, ISBN: 1-904035-97-3.

Sy, P.A., 1997. Doing bioethics in the Philippines: challenges and intersections of cultures and medicines. Proceeding of the UNESCO Asian Bioethics Conference, Nov. 4-8, Kobe, Japan, pp: $1-1$. http://www.upd.edu.ph/ kssp/psy/kobe.html

Tan, M.L., 1987. Usug, Kulam, Pasma: Traditional concepts of health and illness in the Philippines. Alay Kapwa Kilusang Pangkalusugan, Quezon City, ISBN: 9789718565216.

Tan, M.L., 1996. Traditional medical practitioners in the Philippines. College of Social Sciences and Philosophy, University of the Philippines-Diliman, Quezon City, http://www.elib.gov.ph/details.php?uid=d21d9efc6 2f9fd448724aef985dd2fda

Williams, C.C., 2005. The undeclared sector, selfemployment and public policy. Int. J. Entrepr. Behav. Res., 1: 244-257. DOI: $10.1108 / 13552550510603289$
Williams, C.C., 2006. The Hidden Enterprise Culture: Entrepreneurship in the Underground Economy. Edward Elgar, Cheltenham, ISBN: 13: 978-184542-520-3.

Winston, C.M. and V. Patel, 1995. Use of traditional and orthodox health services in urban Zimbabwe. Int. J. Epidemiol., 24: 1006-1012. DOI: 10.1093/ije/24.5.1006

World Health Organization, Regional Office for the Western Pacific, 2001a. Traditional medicine. WHO, Brunei Darussalam. http://www.wpro.who.int/health_topics/traditional_ medicine/overview.htm

World Health Organization. 2001b. Legal status of traditional medicine and complementary/alternative medicine: A worldwide review. WHO, Geneva. http://whqlibdoc.who.int/hq/2001/WHO_EDM_TR M_2001.2.pdf

World Health Organization. 2002. Traditional medicine strategy 2002-2005. WHO, Geneva. http://apps.who.int/medicinedocs/pdf/s2297e/s2297 e.pdf 